American Journal of Pharmaceutical Education 2018; 82 (8) Article 6364.

\title{
RESEARCH
}

\section{Identification of Key Business and Management Skills Needed for Pharmacy Graduates}

\author{
Jill Augustine, PharmD, PhD, MPH, ${ }^{\mathrm{a}}$ Marion Slack, PhD, ${ }^{\mathrm{b}}$ Janet Cooley, PharmD, ${ }^{\mathrm{b}}$ \\ Sandipan Bhattacharjee, PhD, MS, ${ }^{\mathrm{b}}$ Erin Holmes, PharmD, PhD, ${ }^{\mathrm{c}}$ Terri L. Warholak, $\mathrm{PhD}^{\mathrm{b}}$ \\ ${ }^{a}$ Mercer University College of Pharmacy, Atlanta, Georgia \\ ${ }^{\mathrm{b}}$ University of Arizona, Tucson, Arizona \\ ${ }^{\mathrm{c}}$ University of Mississippi, Oxford, Mississippi \\ Submitted February 23, 2017; accepted June 20, 2017; published October 2018.
}

Objective. To identify key business, management, and human resources skills needed by pharmacy graduates.

Methods. Pharmacy preceptors were recruited for inclusion in one of four focus groups. At each focus group, participants were asked to complete a demographic questionnaire and to identify key skills that new graduates need but do not have. Each focus group was audio-recorded, transcribed, de-identified, and categorized using a data dictionary.

Results. Twenty-seven preceptors participated in the focus groups. Fourteen participants had a Doctor of Pharmacy degree. Participants were involved in management positions for a median of 10.5 years (range 5-21 years) and 50\% (median) of their time was devoted to management responsibilities (range $20 \%-80 \%$ ). Seven themes were identified as being most critical: communication, business skills, decision-making and time management, conflict resolution, leadership and professionalism, personnel management, and computer software techniques.

Conclusion. Communication was the most prominent skill identified, followed by decision-making and business knowledge. These skills should be addressed in pharmacy curricula. Future research should focus on how to best teach these skills.

Keywords: student pharmacists, careers, business, management, preceptors

\section{INTRODUCTION}

Pharmacy schools have updated their current curricula to comply with the 2016 Accreditation Council for Pharmacy Education (ACPE) Standards and the 2013 Center for the Advancement of Pharmacy Education (CAPE) Educational Outcomes and to ensure that graduates' knowledge, skills and abilities align with current professional needs. ${ }^{1,2}$ Based on information outlined in the ACPE Standards and CAPE Educational Outcomes, knowledge of business, management, and human resource (HR) skills are expected of new pharmacy graduates.

Both ACPE Standards and CAPE Educational Outcomes infer that pharmacy schools must solicit feedback from alumni and experiential education preceptors on student performance. Preceptors can be defined as instructors

Corresponding Author: Jill Augustine, Mercer University, 3001 Mercer University Dr., Atlanta, GA 30324. Tel: 678547-6738. E-mail: Augustine_jm@mercer.edu

Note: This study was conducted while Dr. Augustine was a doctoral candidate at the University of Arizona College of Pharmacy. or teachers outside of the classroom who oversee the pharmacy practice experiences. Because of the Doctor of Pharmacy curriculum requirements, preceptors spend a lot of time with student pharmacists. ${ }^{3}$ Thus, preceptors can provide feedback on the knowledge and performance of students during clinical practice. Existing research has reported on the use of preceptors to provide the school with feedback on the perceived abilities of their graduates in several areas, including clinical skills, leadership, and pharmacy laws. ${ }^{4}$ Stakeholders provide suggestions for how to improve the curriculum and experiential learning practices. Faculty members and administrators use the results to validate and to improve their curriculum.

Several types of methodologies have been used to assess which business and management skills are necessary for future pharmacy managers. Latif outlined the types of business and management skills essential for future pharmacy managers using a review of the business education literature. ${ }^{5}$ Axworthy and MacKinnon, and Faris and colleagues surveyed managers on the perceived importance of managerial skills based on the American Society of Health-System Pharmacists' (ASHP) supplemental 


\section{American Journal of Pharmaceutical Education 2018; 82 (8) Article 6364.}

standard and learning objectives for residency training in pharmacy practice management. ${ }^{6,7}$ Frenzel and colleagues surveyed advanced pharmacy practice experience (APPE) preceptors on the essential clinical and non-clinical skills for student pharmacists. ${ }^{8}$ To the best of the authors' knowledge, no research has been done to assess pharmacy graduates' business and managerial skill needs using focus groups.

The use of focus groups in the pharmacy education literature is limited. In general, using focus groups can be beneficial in pharmacy research as the group interaction can encourage participants to build on and explore others' ideas. ${ }^{9}$ Additionally, focus groups are advantageous because new issues can be uncovered and the interviewer has the opportunity to ask follow-up and/or clarification questions that could not be easily or consistently done with survey research. ${ }^{9}$ Of the published focus group studies in this area, research on preceptor/stakeholder feedback about the education of student pharmacists is limited to the development of a capstone course and to the conduct of a formative evaluation of the pharmacy courses. ${ }^{10,11}$ In each case, the results provide in-depth information about the design and development of a pharmacy course and how these courses could be improved. Additionally, these study results offer vital feedback to the pharmacy faculty and administrators on educating student pharmacists.

Managerial skills are important for future pharmacy managers. New graduates will be future pharmacy managers. It is important for these future managers to gain knowledge and experience in managerial skills before being placed in a management position. Additionally, while it is clear that business and management skills should be part of the pharmacy curricula, it is still unclear what specific business and managerial skills are vital for new graduates. To prepare student pharmacists, it is necessary to understand what business and management skills are the most important for their possible roles as pharmacy managers.

The primary objective of this study was to determine which business, management, and HR skills pharmacy managers and preceptors feel are important for all student pharmacists to learn. The second objective was to determine what should be measured for each identified skill.

\section{METHODS}

Four cross-sectional focus groups were used to gather information on what business, management, and HR skills pharmacy managers and preceptors felt pharmacy students should have at graduation. The focus groups were hosted over a two-week period with two groups at the university's satellite campus and two groups at the main university campus. Each focus group session lasted from 1 to 1.5 hours.

Participants were recruited from a preceptor contact list on file with the college's experiential education office. Participants were pharmacy preceptors, who were either managers, hospital or community pharmacy supervisors. Pharmacy residents were also invited to participate, since business, management, and HR skills are included in the required competencies areas for all accredited residency programs through ASHP. ${ }^{12}$ Residents may be able to offer a different viewpoint of which skills are used by residents on a daily basis.

Participants were included if they were a preceptor, a registered pharmacist in Arizona, and had a job title that included one of the following designations: manager, lead, chief, or other management position; or were a current first- or second-year pharmacy resident. The researchers wanted to focus on preceptor stakeholders, as faculty members have other means to provide curricular input. Additionally, the researchers wanted participants to be open to comments about perceived educational gaps without judgement or discussion from those directly involved with curriculum development. Participants were excluded if they were paid as a faculty member of the university.

Participants were recruited by email sent to their official email address as listed with the Experiential Education Office. Those who wanted to participate were asked to contact the primary investigator with their preferred focus group date. No incentive was offered for participation in the focus groups.

Upon arrival at the focus group, consent forms were distributed to all potential participants. Once consent was received, paper copies of the questionnaire were distributed to participants. The questionnaire contained demographic questions about the participants' sex, age, year of pharmacy school graduation, degrees and certifications, current managerial role, current employer (type of organization), number of years in management, roles of the people currently managed, number of people in each role managed, amount of time per week spent on management tasks, and if he/she was a preceptor for a pharmacy school or college. Participants were asked a series of open-ended questions regarding which business, management or HR skills were most critical when preparing new graduates for a future managerial role and how they felt these skills should be taught and assessed.

Transcription documents were uploaded into ATLAS. ti qualitative software (Corveillis, OR). Prior to coding, a codebook of anticipated skills was developed. New codes were added as themes/skills emerged from the data. Topic coding was performed in two phases: a general categorization 


\section{American Journal of Pharmaceutical Education 2018; 82 (8) Article 6364.}

followed by a thematic analysis to detect overarching themes. Upon completion of thematic analysis, a conceptual network map was developed to link identified skills and to indicate their relationships.

The questionnaire data were entered into a spreadsheet and responses were analyzed using Stata SE, v12 (College Station, TX) to determine descriptive demographic statistics and frequencies of preceptor and management responsibilities. The university's Institutional Review Board deemed the focus group research as exempt.

\section{RESULTS}

Twenty-seven preceptors who held a managerial position participated in the four focus groups. The attendees represented a variety of practice settings including hospital, managed care, supermarkets, chain pharmacies, and independently owned pharmacies. Eighteen participants managed pharmacists (67\%), 15 managed student pharmacists (56\%), and 17 managed technicians (63\%). Participants were involved in a management role for a median of 10.5 years and reported that $50 \%$ of their time (median) was devoted to management responsibilities. There was an approximately equal number of participants with a Bachelor of Science degree in Pharmacy (BSPharm, $n=13$ ) and with a Doctor of Pharmacy degree (PharmD, $n=14)$. A small number of participants had an advance degree (eg, Master or Doctor of Philosophy $(\mathrm{PhD}), \mathrm{n}=4$ or were board certified $(\mathrm{n}=6)($ Table 1$)$.

Seven themes were identified as shown in Table 2. These themes were: communication (66 mentions), business skills (including hiring/firing; 35 mentions), decisionmaking and time management (34 mentions), conflict resolution and management (26 mentions), leadership (18 mentions), management and directing people (17 mentions), and computer software (11 mentions). Figure 1 shows the network depiction of the major themes and sub-themes. Additionally, specific participant quotes are listed in Appendix A.

Theme 1: Communication skills. Participants often indicated that communication skills, both oral and written, were important for pharmacy graduates. They recommended that all pharmacy graduates must be able to communicate with a variety of parties, including patients, other health care providers, students, managers or company executives, co-workers, colleagues and other employees. Specifically, participants mentioned that graduates should be able to communicate with those who have different types of personalities or perspectives. For example, they felt it was important for graduates to be able to manage the different generations represented in the workforce and to change the message or delivery to target the correct audience. Finally, participants felt that listening skills are a vital communication skill for all graduates.

Participants recommended that students' communication skills be assessed by evaluating their skills in active listening, message clarity and conciseness, appropriate eye contact, and empathy. They also recommended that students be evaluated on their ability to use good writing skills, including using appropriate English spelling and grammar, tailoring the message to the audience, and using correct media to communicate with patients and employees (eg, text messages versus e-mail, or e-mail versus telephone calls).

Theme 2: Business skills. Participants mentioned that knowing how to read and interpret reports such as profit-loss statements, payroll, scheduling, budgets, and other key performance indicators are vital to understanding corporation structure, management, and goals. Additionally, participants felt that graduates should have a mission, vision, and goals for their team or department and that they should know the mission, vision, and goals of their employer as these are vital to making businessrelated decisions.

Participants also mentioned that other HR-related skills are needed for graduates. Specifically, they indicated that graduates should know what benefits are offered by their employers, be able to hire and fire employees, participate in succession planning, and understand marketing. They also indicated that it's important for new and current managers to know what company resources are available and how to access additional resources. This includes directing patients or employees to additional resources within and outside of the company. Finally, participants mentioned that pharmacy is a customer-service profession and new pharmacists and managers should have the ability to interact well with their customers.

Within business skills, participants indicated that students should be evaluated on their knowledge of HR metrics and resources, including inventory management, establishing yearly metrics that can drive the budget, and ensuring that the business is profitable.

Theme 3: Decision-making and time management. Decision-making and time management are themes that were frequently mentioned together. Key skills within decision-making included the ability to critically consider a problem and find, develop, or consider potential solutions. As one participant summarized that good decision-making involves a manager being able to see the advantages and disadvantages of every decision (Appendix 1). As part of decision-making, participants indicated that the ability to develop creative solutions was becoming more important. In addition, knowing when to ask for help from either the manager or employees was 


\section{American Journal of Pharmaceutical Education 2018; 82 (8) Article 6364.}

Table 1. Demographic Characteristics of Focus Group Participants $(\mathrm{n}=27)$

\begin{tabular}{|c|c|}
\hline \multicolumn{2}{|l|}{ Characteristics } \\
\hline & $\mathbf{N}(\%)^{\mathbf{a}}$ \\
\hline \multicolumn{2}{|l|}{ Focus Group Number } \\
\hline 1 & $7(26)$ \\
\hline 2 & $3(11)$ \\
\hline 3 & $11(41)$ \\
\hline 4 & $6(22)$ \\
\hline \multicolumn{2}{|l|}{ Job Title ${ }^{b}$} \\
\hline Owner & $1(4)$ \\
\hline Manager & $6(22)$ \\
\hline Pharmacist in charge & $3(11)$ \\
\hline Resident & $2(7)$ \\
\hline $\begin{array}{l}\text { Other (eg, chief pharmacist, clinical } \\
\text { pharmacist, director, supervisor, } \\
\text { vice president, staff pharmacist) }\end{array}$ & $16(59)$ \\
\hline \multicolumn{2}{|l|}{ Employer } \\
\hline Hospital & $4(15)$ \\
\hline Managed care organization & $6(22)$ \\
\hline Supermarket & $2(7)$ \\
\hline Chain & $7(26)$ \\
\hline Mass merchant & $0(0)$ \\
\hline Independent & $2(7)$ \\
\hline $\begin{array}{l}\text { Other patient care provider } \\
\text { (eg, community health center, } \\
\text { mail order, medication therapy } \\
\text { management center, university) }\end{array}$ & $8(30)$ \\
\hline Other non-patient care provider & $1(4)$ \\
\hline $\begin{array}{l}\text { Preceptor at another school besides the } \\
\text { University of Arizona }\end{array}$ & $21(78)$ \\
\hline \multicolumn{2}{|l|}{ Gender } \\
\hline Male & $14(54)$ \\
\hline Female & $12(46)$ \\
\hline \multicolumn{2}{|l|}{ Year graduated from pharmacy school } \\
\hline 1970 or before & $1(4)$ \\
\hline 1971 to 1980 & $4(15)$ \\
\hline 1981 to 1990 & $5(19)$ \\
\hline 1991 to 2000 & $7(26)$ \\
\hline 2001 to 2010 & $7(26)$ \\
\hline 2010 to 2015 & $3(11)$ \\
\hline \multicolumn{2}{|l|}{$\begin{array}{l}\text { Degree or certification (participants may } \\
\text { select all that applied) }\end{array}$} \\
\hline $\begin{array}{l}\text { Bachelor of Science in Pharmacy (BS } \\
\text { Pharm) }\end{array}$ & $13(48)$ \\
\hline Doctor of Pharmacy (PharmD) & $14(52)$ \\
\hline Board Certification (eg, BCPS, BCOP) & $6(22)$ \\
\hline Master's degree (eg, MBA, MPH, MS) & $3(11)$ \\
\hline Doctor of Philosophy (PhD) & $1(4)$ \\
\hline Other certification, not listed & $3(11)$ \\
\hline $\begin{array}{l}\text { Number of employees that participants } \\
\text { manage }\end{array}$ & Median (Range) \\
\hline Student pharmacists & $15(1-100)$ \\
\hline Pharmacists & $18(1-240)$ \\
\hline
\end{tabular}

(Continued)
Table 1. (Continued)

\begin{tabular}{|c|c|}
\hline \multicolumn{2}{|l|}{ Characteristics } \\
\hline & Median (Range) \\
\hline First-year residents & $5(1-8)$ \\
\hline Second-year residents & $0(\mathrm{~N} / \mathrm{A})$ \\
\hline Graduate students & $1(4)$ \\
\hline Technicians & $17(1-325)$ \\
\hline Other health care professional students & $2(2)$ \\
\hline Other health care professionals & $1(25)$ \\
\hline \multirow[t]{2}{*}{ Other staff } & $3(1-25)$ \\
\hline & Median (IQR) \\
\hline Percent of time spent on management & $50(20-80)$ \\
\hline Number of years in management & $10.5(5-21)$ \\
\hline Years in current management position & $3(1-7.5)$ \\
\hline \multicolumn{2}{|c|}{$\begin{array}{l}\text { Abbreviations: BCPS= Board Certified Pharmacotherapy Specialist, } \\
\text { BCOP= Board Certified Oncology Pharmacist, MBA= Master of } \\
\text { Business Administration, MPH=Master of Public Health, } \\
\text { MS=Master of Science, IQR = Interquartile Range } \\
\text { a Percentages may not equal } 100 \% \text { due to rounding } \\
{ }^{b} \text { Participants were allowed to select more than one position title if } \\
\text { applicable }\end{array}$} \\
\hline
\end{tabular}

mentioned in all focus groups. Participants mentioned new graduates asking questions and asking for help before completing any task, especially if there is any confusion.

When discussing time management, participants felt that the ability to delegate tasks and responsibilities was important for new graduates. As one participant mentioned that it can be difficult for pharmacists to delegate tasks, especially for those tasks that are the pharmacists' responsibilities. However, the participant noted that it is important to delegate responsibilities to others in order to continue to focus on their primary responsibilities (Appendix 1). One particular point about time management was for managers to ensure that meetings are productive, efficient, and end on time.

Participants felt that students should be assessed on their ability to complete tasks or projects on time and their ability to share decision rationale and/or the decisionmaking process with their teams. Lastly, participants said that because a graduate should have established priorities, assessing students' abilities to set priorities is important.

Theme 4: Conflict resolution and management. Participants felt that key conflict resolution skills include good listening skills, humility, planning, and the ability to evaluate self and others. Listening skills are vital as they prevent managers from making rash decisions or judgments. Being willing to listen to and consider both sides of a conflict was also mentioned as an important managerial skill.

Participants stated that new graduates need to be humble and realize that not all decisions are personal. They mentioned that it is important for new graduates to realize that they need to be humble to complete the tasks 
American Journal of Pharmaceutical Education 2018; 82 (8) Article 6364.

Table 2. Major Themes Identified by Focus Group Participants

\begin{tabular}{|c|c|c|}
\hline Theme & Skills Identified & No. of Times Theme was Mentioned \\
\hline$\overline{\text { Communication }}$ & $\begin{array}{l}\text { Oral and written } \\
\text { Interpersonal and generational } \\
\text { Message delivery }\end{array}$ & 66 \\
\hline Decision-making and Time Management & $\begin{array}{l}\text { Problems-solving } \\
\text { Delegation }\end{array}$ & 35 \\
\hline Business Skills & $\begin{array}{l}\text { Understanding business reports } \\
\text { Vision and goal setting } \\
\text { Budgeting }\end{array}$ & 34 \\
\hline Conflict Resolution & $\begin{array}{l}\text { Good listening skills } \\
\text { Humility } \\
\text { Self- and peer-evaluation }\end{array}$ & 26 \\
\hline Leadership \& Professionalism & $\begin{array}{l}\text { Professional organization involvement } \\
\text { Professional development } \\
\text { Networking } \\
\text { Lifelong learning }\end{array}$ & 18 \\
\hline Computer Software Techniques & $\begin{array}{l}\text { Sorting data } \\
\text { Spreadsheet equations } \\
\text { Pivot tablets }\end{array}$ & 11 \\
\hline
\end{tabular}

of other team members to ensure that the team is united in helping patients and in providing care (Appendix 1). Finally, most of the participants mentioned that new graduates should have the ability to competently complete self- and peer-evaluations. This evaluation process includes annual reviews, providing feedback to employees and managers, and providing feedback on feedback. When discussing feedback, the participants unanimously agreed that peer-feedback should be constructive. As one participant summarized, being able to provide constructive feedback is vital to improving future experiences (Appendix 1).

The main conflict resolution skill that participants felt students should be assessed was their ability to resolve problems and conflicts while being "calm under pressure." Participants also felt that being able to rationally explain to another employee why conflict is occurring is an important skill to assess.

Theme 5: Leadership \& Professionalism. A large part of leadership involves professionalism. Leadership was mentioned 18 times and professionalism was mentioned 22 times during the focus groups. Participants mentioned that new graduates were often appropriately dressed, but were usually lacking in Internet and email professionalism; this was especially apparent when the new graduates were of similar age or personality to their co-workers. Therefore, the participants recommended that new graduates should be well versed in and adhere to appropriate Internet and cellphone procedures, especially during work hours. Another point of professionalism brought up by the participants was that it is important for new graduates to continue to be involved in professional pharmacy organizations. Participants noted that it is important to be active because it increases knowledge and participation in policy, advocacy, and networking within the pharmacy profession. Finally, participants indicated that new graduates should be aware that lifelong, self-directed learning is needed for professional success. The world of pharmacy practice is constantly evolving and developing. Participants felt that graduates should devote themselves to learning. A participant mentioned that new graduates will have to continue to learn as new medications and guidelines are released and become available (Appendix 1).

Participants indicated that leadership skills on which students should be assessed should include professional behavior, community involvement, professional volunteerism, and ability to build a successful and accomplished team.

Theme 6: Managing and directing others. The themes of managing and directing others were often discussed together. When describing this skill set, participants discussed that they felt that graduates should have the ability to keep other employees and themselves organized and task oriented. They indicated that it is essential that tasks and/or projects be completed on time or with appropriate and timely updates, while the employee continues to complete 


\section{American Journal of Pharmaceutical Education 2018; 82 (8) Article 6364.}

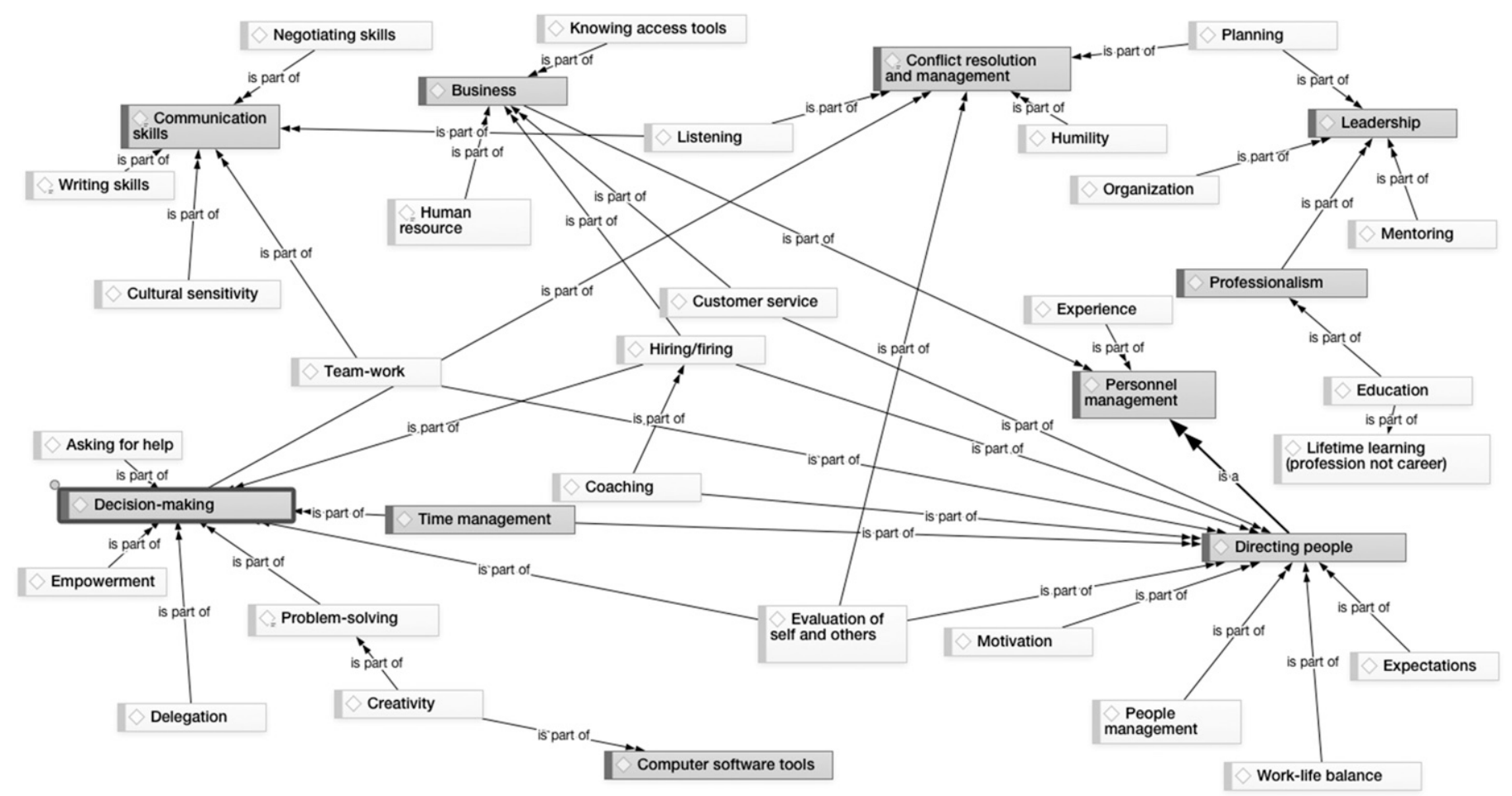

Figure 1. Thematic Network of Skills Identified by Pharmacy Preceptors

*As shown in the network theme map, many of the top themes overlap with other themes.

day-to-day responsibilities. When directing people, participants mentioned that it is important for pharmacy graduates to have the ability to set expectations of others, to motivate employees when necessary, and to develop a work-life balance. Another key skill under this theme was the ability to involve their team in tasks, projects, and the decision-making process. These teams could be the interdisciplinary team that are organized around patient care or departmental teams that develop in the workplace. Finally, several participants mentioned that understanding team members, whether they be subordinates, colleagues, or other professionals is vital for graduates. By understanding the morale of the team, a graduate should have the ability to develop rapport and help direct, manage, motivate, and coach others. Additionally, this skill can facilitate workflow and networking with individuals outside of the department.

According to participants, one of the key components of managing and directing others that should be assessed was how well the team works together, especially when the manager is not present, and if there are "bottlenecks" in the workflow. By knowing and understanding the team and team dynamics, the workflow process should run smoothly and conflicts should be minimal.

Theme 7: Computer software tools. Participants identified computer software skills as essential for all graduates. Examples of essential computer skills for new graduates include: developing and using pivot tables, performing simple arithmetic computations within spreadsheets, and sorting within a spreadsheet. Participants also felt that new graduates should be able to design an effective presentation. This includes paying attention to the number of words per slide, the layout of information within a presentation, and slide design so that the presentation provides accurate and appropriate information. Finally, members of two focus groups mentioned that it is important for graduates to understand Six Sigma or lean management strategies.

Participants found it difficult to articulate how to assess computer software skills. They felt these skills could be assessed by evaluating students' ability to use software to solve problems. It was also mentioned that creativity should be used when using computer software. For example, when using presentation software such as Microsoft PowerPoint (Redmond, WA), participants felt that students should be able to creatively use it to deliver education and information.

\section{DISCUSSION}

This study identified key business, management, and HR skills that pharmacy preceptors thought were most critical when preparing new graduates for a future 


\section{American Journal of Pharmaceutical Education 2018; 82 (8) Article 6364.}

managerial role. Thematic analysis of the focus group transcripts resulted in the development of seven major themes. Communication was the top skill identified. This included both written and oral communication among colleagues, subordinates, and management personnel. Several studies have identified managerial communication as a vital skill for all pharmacy graduates. Latif found that communication was the most frequently cited managerial skill in business education literature. ${ }^{5}$ Axworthy and colleagues reported that being able to "communicate effectively when speaking or writing" was a vital skill for Canadian managers. ${ }^{6}$ Frenzel and colleagues reported that communication was a vital skill for United States pharmacists. ${ }^{8}$ While several studies have found that managerial communication is a vital skill, it remains unclear if this skill has been incorporated into pharmacy curricula as little follow-up on this has been published. ${ }^{6,8}$

After communication, decision-making and time management was the next most frequent skill mentioned. Because the decision-making process seems intuitive, it is rarely discussed. Due to the importance of understanding the process of decision-making and problem solving, the skill was included in the Association to Advance Collegiate Schools of Business (AACSB) 2013 Assurance of Learning Standards and has been frequently mentioned in the business education literature. ${ }^{13,14}$ Additionally, the skill was added as an AACP CAPE Educational outcome and is in the 2016 ACPE Standards. ${ }^{1,2}$ Despite the inclusion of the skill in these accreditation documents, it still remains a need in the pharmacy curriculum and in the pharmacy education literature. ${ }^{15}$

The use of focus groups allowed for in-depth feedback from preceptors on management topics and skills that pharmacy students need to be competitive in the job market. In the focus groups, the moderator asked questions that were geared to provide in-depth feedback and get instant clarification on responses. This provided a broader depth to the information collected on the types of skills needed. This research allowed preceptors to provide vital feedback to the pharmacy college. All of the focus group participants were pharmacists who were working with students and new graduates. Many of the participants have been in management roles for at least 5 years and had experience working with new graduates. As with previous research using preceptors, these participants provided a practical view of what skills were most critical for new graduates and suggestions on how to improve the curriculum. ${ }^{4}$

Adequate assessment of skills is just as vital in pharmacy education as learning the skill. By conducting appropriate assessment, an educator is able to determine if a student understands and applies the skill correctly. Assessment measures should also be developed to match the learning objectives. The participants provided insight into how each skill could be assessed.

The thematic analysis of the business, management, and HR skills identified provided an initial picture of the skills that preceptors feel new pharmacists needed. As key stakeholders in assisting with the development and education of student pharmacists, preceptors are ideal for providing feedback and guidance of new topics that should be included in pharmacy curricula. ${ }^{1}$ Additionally, preceptors in management roles can provide real-world, practical knowledge about the application of these skills. The themes and skills identified from the focus groups provided practical feedback on quality improvement of the college's management education. Finally, preceptor feedback should be incorporated into the assessment of the pharmacy program. Through this research, preceptors were actively involved in providing important feedback for the college on how to make student pharmacists prepared for the job market at graduation.

Faculty members, administrators, and instructional designers should focus on how to appropriately incorporate these skills into the curriculum. There should be a thorough review of the curriculum to determine if these skills are being taught. If a skill is being taught, faculty members should consider if changes are needed to address the perceived need for additional education. If a skill is not being taught, faculty members (especially members of the curriculum committee) should provide suggestions on where these skills can be incorporated into existing courses. There are many examples on the design, development, and assessment of pharmacy management courses in the published literature. ${ }^{16-22}$

This study has limitations. First, this study was based on the opinion of preceptors associated with one pharmacy college. Second, because of the convenience sample, only a small number of preceptors volunteered to participate in the focus group. The four focus groups were held on different days and in the two locations of the largest number of preceptors to increase involvement. More focus groups or targeted focus groups could have generated different responses.

\section{CONCLUSION}

Pharmacy education has focused on the inclusion of the knowledge, skills, and abilities outlined in the AACP CAPE 2013 Educational Outcomes ${ }^{2}$ and the 2016 ACPE Standards. ${ }^{1}$ This study provides evidence of additional skills that should be considered for inclusion into the curriculum. Seven major themes were identified as being necessary for all pharmacy graduates to know and understand. Schools and colleges of pharmacy should use this information to review their curriculum to determine the 


\section{American Journal of Pharmaceutical Education 2018; 82 (8) Article 6364.}

inclusion of these skills in pharmacy education. Additionally, assessment measures identified in this research can serve as an initial indicator for reviewing how these skills should be taught and assessed. Through the inclusion of these skills in the curriculum, pharmacy schools and colleges are preparing students to handle managerial issues and concerns that happen daily at their workplace. Therefore, it is vital to provide students the education to understand and handle these situations.

\section{ACKNOWLEDGMENTS}

The authors would like to thank the University of Arizona College of Pharmacy Experiential Education Office staff for their help with this research as well as the preceptors associated with the University of Arizona College of Pharmacy. This work was partially supported by the University of Arizona Graduate and Professional Student Council Research Grant, Tucson, AZ. This research was previously presented as a poster at the 2016 American Pharmacists Association (APhA) annual meeting in Baltimore, MD.

\section{REFERENCES}

1. Accreditation Council for Pharmacy Education. Accreditation standards and key elements for the professional program in pharmacy leading to the doctor of pharmacy degree. Standards 2016. https:// www.acpe-accredit.org/pdf/Standards2016FINAL.pdf. Accessed February 2, 2017.

2. Medina MS, Plaza CM, Stowe CD, et al. Center for the Advancement of Pharmacy Education 2013 educational outcomes. Am J Pharm Educ. 2013;77(8):Article 162.

3. Skrabal MZ, Jones RM, Nemire RE, et al. National survey of volunteer pharmacy preceptors. Am J Pharm Educ. 2008;72(5): Article 112.

4. Sealy PI, Williams S, Sa B, Ignacio DN, Extavour RM. Stakeholder perspectives on outcome expectations of pharmacy graduates from a Caribbean school of pharmacy. Am J Pharm Educ. 2013;77(5):Article 99.

5. Latif DA. Model for teaching the management skills component of managerial effectiveness to pharmacy students. Am J Pharm Educ. 2002;66(4):377-381

6. Axworthy S, MacKinnon NJ. Perceived importance and selfassessment of the skills of Canada's health-system pharmacy managers. Am J Health System Pharm. 2002;59(11):1090-1096.

7. Faris RJ, MacKinnon GE, MacKinnon NJ, Kennedy PL. Perceived importance of pharmacy management skills. Am J Health System Pharm. 2005;62(10):1067-1072.
8. Frenzel J, Eukel H, Neville M, et al. Essential skills for pharmacy graduates reported by advanced pharmacy practice experience preceptors. Curr Pharm Teach Learn. 2015;7(5):700-704.

9. Kitzinger J. Focus groups. In: Pope C, Mays N, eds. Qualitative Research in Health Care. Oxford, UK: Blackwell Publishing Ltd; 2007:21-31.

10. Lee JK, Cooley JH, Tanner NE, Hanauer CN, Schiefer DM, Herrier RN. Development of a pharmacy capstone course from focus groups to advanced patient care. Am J Pharm Educ. 2014;78(8): Article 156.

11. Bhavsar VM, Bird E, Anderson HM. Pharmacy student focus groups for formative evaluation of the learning environment. $A m J$ Pharm Educ. 2007;71(2):Article 22.

12. American Society of Health-System Pharmacist. Required competency areas, goals, and objectives for postgraduate year one (PGY1) pharmacy residencies. https://www.ashp.org/-/media/assets/ professional-development/residencies/docs/required-competencyareas-goals-objectives. Accessed February 8, 2017.

13. Association to Advance Collegiate Schools of Business. Eligibility procedures and accreditation standards for business accreditation. https://www.aacsb.edu/accreditation/standards/ business. Accessed on February 2, 2017.

14. Latif DA. A management skills course for pharmacy students. Am J Pharm Educ. 2004;68(1):Article 3.

15. Mospan CM. Management education within pharmacy curricula: a need for innovation. Curr Pharm Teach Learn. 2017; 9(2):171-174.

16. Laverty G, Hanna LA, Haughey S, Hughes C. Developing entrepreneurial skills in pharmacy students. Am J Pharm Educ. 2015;79(7):Article 106.

17. Lawrence LW. Applying case methodology to teach pharmacy administration concepts. Pharm Educ. 2002;2(3):101-105.

18. Rollins BL, Broedel-Zaugg K, Reiselman J, Sullivan D.

Assessment of pharmacy students' perceived business management knowledge: would exclusion of business management topics be detrimental to pharmacy curricula? Curr Pharm Teach Learn. 2012; 4(3):197-201.

19. Monk-Tutor MR. Development of a problem-based learning course in human resources management. Am J Pharm Educ. 2001; 65(1):64-73.

20. Davies MJ, Fleming H, Jones R, Menzie K, Smallwood C, Surendar S. The inclusion of a business management module within the master of pharmacy degree: a route to asset enrichment? Pharm Pract (Granada). 2013;11(2):109-117.

21. Singleton JA, Nissen LM. Teaching pharmacy students how to manage effectively in a highly competitive environment. Pharm Educ. 2014;14(1):21-25.

22. Perepelkin J. Redesign of a required undergraduate pharmacy management course to improve student engagement and concept retention. Am J Pharm Educ. 2014;76(10):Article 201. 


\section{American Journal of Pharmaceutical Education 2018; 82 (8) Article 6364.}

Appendix 1. Participant Quotations for Business and Management Themes

Theme Number and Title

Theme 2: Business skills

Theme 3: Decision-making and time management

Theme 4: Conflict resolution and management

Theme 5: Leadership \& Professionalism

\section{Participant Quotations}

This is my pharmacy. I know that we fill prescriptions, but where do I want to go? What kind of pharmacy do I want to be in 10 years? What are we going to be doing? What other services can I offer? By understanding this [through a mission, vision, and goals], I can answer these questions.

Map out the pros and cons for every situation, then try to figure out which way [you] want to go.

We like our new graduates to ask questions, don't just do [a task]. It is so much easier the first time around and to answer questions, than to fix the problem because they did not ask for help.

The hardest thing for me is to let go of tasks that you are responsible for ... So it is really learning a way to organize yourself so that you can pass [a task] along to someone else.

You can be a better manager if you understand someone's situation.

When [graduates] get out of school, they think that they are high above everyone else. They need to realize that they should be able to do the tasks of other team members, like taking out the trash. This type of behavior is helpful for creating unity among teams.

New graduates, especially those who go into residency, are going to be asked to give feedback on every aspect of their experience. Understanding how to give constructive feedback helps everyone with improving the experience for current and future residents.

Calm under pressure.

New graduates should be able to stay abreast of changes within their practice. . you do not know everything at graduation. New graduates must continue to learn. 